\title{
Comunicação pública como prática de responsabilidade social das organizações públicas
}

Public communication as a practice of social responsibility by public organizations

Comunicación pública como práctica de responsabilidad social de las organizaciones públicas

\section{Gisele Rosso}

- Mestre em Comunicação pela Universidade Federal do Paraná (UFPR)

- Especialista em Comunicação Empresarial pela Pontifícia Universidade Católica do Paraná (PUC-PR)

- Graduada em Comunicação Social - Jornalismo pela Universidade Estadual de Ponta Grossa (UEPG)

- Assessora de comunicação do Ministério Público do Trabalho no Paraná (MPTPR)

- Analista de Comunicação da Embrapa

- Áreas principais de atuação: comunicação pública, assessoria de imprensa

- E-mail: rosso.gisele@gmail.com

\section{Celsi Brönstrup Silvestrin}

- Doutora em Ciências da Comunicação pela Escola de Comunicação e Artes da Universidade de São Paulo (ECA-U̧SP)

- Mestre em Comunicação Social pela Universidade Metodista de São Paulo (UMESP)

- Especialista em Marketing Empresarial pela Universidade Federal do Paraná (UFPR)

- Bacharel em Comunicação Social, habilitação Relações Públicas, pela Universidade Federal de Santa Maria (UFSM)

- Professora do Programa de Mestrado em Comunicação da UFPR, integrando a linha de pesquisa Comunicação, política e atores coletivos

- Integrante dos Grupos de Estudos: Comunicação e Mobilização Política e Comunicação Organizacional - Estratégias e Processos

- Organizadora da obra Gênero plural: um debate interdisciplinar, em parceria com Miriam Adelman

- E-mail: celsi@matrix.com.br 


\section{Resumo}

O artigo propõe o uso da comunicação pública na gestão pública como forma de exercer a responsabilidade social. Analisa brevemente a correlação existente entre ambas, fundamentando aspectos teóricos relevantes sobre o conceito da comunicação pública. Demonstra operacionalmente essa prática, trazendo resultados da pesquisa realizada no Ministério Público do Trabalho no Paraná, ao evidenciar que a opção pela comunicação pública, de fato, promove a responsabilidade social ao favorecer a participação e os interesses da sociedade, na exigência da accountabillity e no alastramento da esfera pública.

PALAVRAS-CHAVE: COMUNICAÇÃO PÚBLICA • RESPONSABILIDADE SOCIAL • ORGANIZAÇÕES PÚBLICAS • INTERESSE PÚBLICO • RELEASES.

\section{Abstract}

The article proposes using public communication in public management as a means to exercise social responsibility. It briefly analyzes the correlation between both of them, based on relevant theoretical aspects concerning the concept of public communication. It shows this practice operationally, bringing search results held at the Labor Public Prosecutor's Office in Paraná, to highlight that the choice of public communication, in fact, promotes social responsibility by encouraging participation and interests of society in the demand for accountabillity and in diffusion of public sphere.

KEYWORDS: PUBLIC COMMUNICATION • PUBLIC INTEREST • PUBLIC ORGANIZATION • SOCIAL RESPONSIBILITY • RELEASES

\section{Resumen}

El artículo propone el uso de la comunicación pública en la gestión pública como una forma de ejercer la responsabilidad social. Analiza la correlación existente entre ambas, fundamentando aspectos teóricos relevantes sobre el concepto de la comunicación pública. Demuestra operacionalmente esa práctica, trayendo los resultados de la investigación realizada en el Ministerio Público del Trabajo en el estado de Paraná, Brasil, al demostrar que la opción por la comunicación pública, de hecho, promueve la responsabilidad social al favorecer la participación y los intereses de la sociedad, en la exigencia de la accountabillity y en la propagación de la esfera pública.

PALABRAS CLAVES: COMUNICACIÓN PÚBLICA • INTERÉS PÚBLICO • ORGANIZACIONES PÚBLICAS • RESPONSABILIDAD SOCIAL • RELEASES 

om o amadurecimento da democracia brasileira os níveis de exigência da sociedade se intensificam também em relação aos órgãos públicos. A Constituição Federal de 1988, conhecida como Constituição Cidadã, abriu espaços à defesa de direitos, à ampliação da participação e à transformação do papel do estado em relação à sociedade. Com as conquistas, a população tem à disposição instrumentos que Ihe permitem exercer o papel de protagonista de mudanças políticas e sociais.

Diante desse cenário mais democrático e participativo, depois de um longo período de repressão durante mais de vinte anos de ditadura no Brasil, as instituições públicas, sobretudo, precisam atentar para as demandas da população e propiciar-Ihe mecanismos de inclusão na vida pública, possibilitando sua interação e o diálogo. É nesse contexto que percebemos a contribuição e o desempenho do papel da responsabilidade social, cujo impacto reverterá positivamente sobre a própria organização e, principalmente, sobre a vida dos indivíduos que dela dependem.

O economista e político Cézar Busatto (2008, p. 2) entende que a responsabilidade social se faz presente na gestão pública, quando ela está capacitada a:

\begin{abstract}
a)Assegurar a cada um dos brasileiros seus direitos individuais, coletivos e sociais; b) submeter as políticas públicas nas áreas econômica e financeira a prioridades e metas de melhoria social; c) efetivar iniciativas planejadas e transparentes, integradas com totalidade dos poderes públicos, por meio de parcerias sociais com terceiro setor e a iniciativa privada, visando à implementação de políticas públicas, planos, programas, projetos e ações eficazes descentralizados; d) promover políticas públicas que tenham por base diagnósticos atualizados, sistemas de acompanhamento, avaliação prestação de contas permanentes, de modo a prevenir riscos e corrigir desvios, capazes de afetar o cumprimento das metas de melhoria dos indicadores sociais; e) proporcionar a valorização e a capacitação dos servidores públicos como agentes empreendedores fundamentais da responsabilidade social na gestão pública.
\end{abstract}

Essa descrição nos leva a perceber que o conceito de responsabilidade social cada vez mais ganha significado e relevância na gestão pública, principalmente no que se refere ao enfrentamento de questões sociais. Embora muitas das práticas da responsabilidade social empresarial possam ser absorvidas na gestão pública, tal como a necessidade da definição de princípios e valores condizentes com os anseios da sociedade, bem como o compromisso em manter um relacionamento ético e transparente com os públicos internos e externos da organização, há especificidades próprias da administração pública. Enfatiza-se aqui a accountability, cuja concepção favorece a legitimidade da atuação de um órgão público, que ao prestar contas e justificar as ações está exercendo a responsabilidade social, estimulando a cidadania ativa e corresponsável que propicia a participação e o envolvimento do cidadão, em um processo de discussão simétrico que busca o equilíbrio entre as partes interessadas.

Assim, é possível considerar que o exercício da responsabilidade social em órgãos públicos aponta para a existência de um interesse comum entre os envolvidos, o qual, para ser legítimo, 


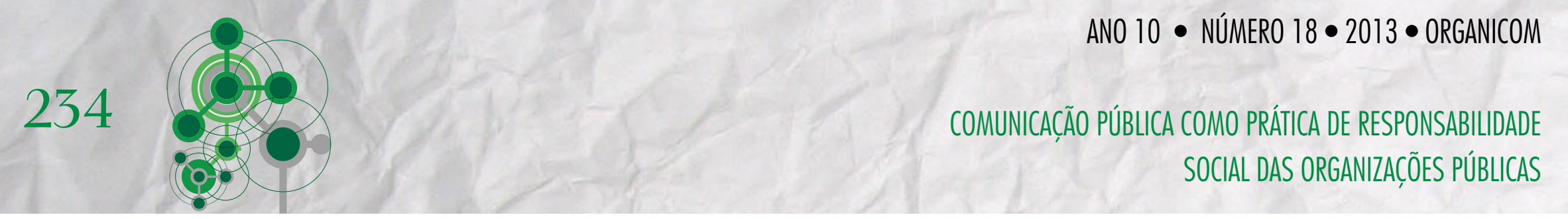

deverá resultar de um processo deliberativo, como bem enfatiza Rousiley Maia (2008, p. 166). Ou seja, a prática da responsabilidade social é condição sine qua non também nos processos de deliberação pública cada vez mais frequentes em uma sociedade democrática, principalmente tratando-se de instituições com poder público, cujas atividades e decisões afetam a coletividade.

Nesse processo de evolução da prática democrática, entendemos a comunicação pública como fundamental na ampliação e no fortalecimento da esfera pública e no avanço da cidadania para a efetivação da capacidade de articulação e de ação da sociedade. Consideramos possível, por meio dela, estimular a participação de indivíduos pertencentes a diferentes grupos em um reconhecimento da diversidade cultural, favorecendo a discussão e a deliberação sobre temas de interesse coletivo. Nesse contexto, o papel da comunicação na sua forma mais ampla, ou seja, não restrita à ação da mídia, ou no seu aspecto instrumental na articulação de públicos internos e externos, é de suma importância para qualquer organização, mas que toma uma dimensão mais significativa e relevante para a sociedade e o cidadão quando a opção é pela comunicação pública, principalmente tratando-se do setor público. Sob essa perspectiva, consideramos que a adoção da comunicação pública por órgãos públicos favorece uma gestão socialmente responsável.

Assim, o objetivo nessa abordagem é entender a comunicação pública e argumentar sobre seu uso da como uma prática de responsabilidade social e como isso se expressa especialmente nos processos comunicativos desenvolvidos no Ministério Público do Trabalho no Paraná.

\title{
COMUNICAÇÃO PÚBLICA LEGITIMADA PELO INTERESSE PÚBLICO
}

O termo comunicação pública se destaca no Brasil, principalmente após o período de redemocratização, quando seu estudo se desvinculou do papel exclusivo de comunicação governamental. A principal proposta da comunicação pública é a de ser uma comunicação de interesse público, independentemente se sua origem parte de uma instituição privada ou de uma pública. Segundo Elizabeth P. Brandão (2009, p. 9), nenhuma das concepções sobre o significado da expressão "comunicação pública" apresenta grandes diferenças quanto ao entendimento de Pierre Zémor (1995) sobre o conceito. De acordo com a autora,

\begin{abstract}
dentre os múltiplos significados da expressão comunicação pública, é possível encontrar um ponto comum de entendimento que é aquele que diz respeito a um processo comunicativo que se instaura entre o estado, o governo e a sociedade com o objetivo de informar para a construção da cidadania. É com este significado que no Brasil o conceito vem sendo construído.
\end{abstract}

Basicamente, trata-se da mesma caracterização de Zémor (1995) sobre comunicação pública, ou seja, legitimada pelo interesse público e centrada no cidadão. Essa comunicação diz respeito à troca e à partilha de informações relevantes ao indivíduo na vida em sociedade. Ainda, segundo Maria José da Costa Oliveira (2004, p. 199), "a comunicação pública assume o desafio de 
promover a educação com fim social, aproximar os diferentes setores, e desenvolver instrumentos de prestação de contas, informação e conscientização junto à sociedade", atuando como interlocutora entre os diferentes entes sociais, em prol do interesse público.

Mariângela F. Haswani (2009) aponta que existe uma distinção entre a comunicação pública realizada por sujeitos públicos e a realizada por sujeitos de direito privado. Segundo ela, a distinção é o dever ou o voluntarismo desses sujeitos que intervêm no âmbito da comunicação pública. Para Patrícia C. Reis (2011, p. 189), a comunicação pública é compreendida adequadamente quando se refere à comunicação em órgãos públicos. No entanto, ela admite que algumas estratégias adotadas por empresas privadas também são consideradas comunicação pública, como quando se referem a "práticas de responsabilidade social e sustentabilidade ambiental, econômica e cultural dessas corporações nos seus entornos e/ou nas comunidades que de alguma forma são impactadas pelo modelo de negócio ou que podem impactá-lo". No seu entender, as empresas privadas também têm a responsabilidade de comunicar priorizando o interesse público. Ações praticadas ou deixadas de praticar por elas afetam a coletividade, portanto, não há como negar a obrigação em publicizar seus atos. Nesse cenário particular, a expressão mais usada é responsabilidade social, em lugar de interesse público.

Graça F. Monteiro (2009) observa que a singularidade da comunicação pública não está no emissor, mas na mensagem transmitida. Para a autora, a relevância está no interesse público, isto é, o que precisa prevalecer na mensagem o interesse de todos em relação ao particular, sejam os emissores o estado, as empresas privadas ou as organizações públicas. A mensagem de interesse público contribui para o desenvolvimento do indivíduo como cidadão, possibilitando reflexão e ação em relação a temas que se referem à vida em sociedade: governo, educação, trabalho, saúde - enfim, o que diz respeito ao bem comum.

Além de garantir a informação e o interesse público na mensagem, cabe enfatizar que das várias características do conceito de comunicação pública, distingue-se a sua indissociabilidade dos agentes envolvidos no processo comunicacional, conforme frisa Heloiza Matos (2009a, p. 123), aspecto fundamental na constituição da esfera pública. Como, então, exercer responsabilidade social num ambiente público em que essa possibilidade não se concretiza? É aí que se traduz a principal contribuição do processo de comunicação pública no exercício da responsabilidade social em órgãos públicos.

Matos (2009b, p. 52) destaca a exigência da participação dos cidadãos como "produtores ativos no processo" quando se relaciona à comunicação pública. O cidadão não é informado apenas, mas chamado a participar, a discutir o que é de seu interesse. Ainda segundo a autora, o entendimento da comunicação pública voltada para as trocas comunicativas entre instituições e sociedade é recente, acontecendo somente a partir da década de 1990. Para que a interlocução entre esses atores aconteça, "é preciso criar espaços de discussão e deliberação sobre temas 
políticos e sociais, espaços capazes de viabilizar a formulação de demandas e sua consequente repercussão no governo, na sociedade e na mídia" (Matos, 2011, p. 45). A criação de fóruns e ouvidorias, a realização de audiências públicas, de mobilizações, entre outros mecanismos de comunicação com a sociedade, são exemplos desses espaços.

Com base nas funções da comunicação pública estabelecidas por Zémor (1995), que atuam como parâmetro para apreender a efetivação desse processo na prática, é importante sinalizar alguns aspectos nos quais as instituições públicas buscam se concentrar para fazer comunicação pública. Entre os quesitos estão: informar, isto é, levar os assuntos ao conhecimento da população, prestar contas à sociedade e valorizar as atividades estatais; ouvir as demandas, as dúvidas e as expectativas do cidadão; fomentar e fortalecer o debate e a participação política; fortalecer as relações sociais. Todas essas funções objetivam responsabilizar a instituição pela promoção do diálogo com a sociedade, disponibilizando informação e conhecimento ao público para sua efetiva participação no que é de interesse comum.

Para Ana Lucia Novelli (2006, p. 77) a comunicação pública praticada pela administração pública, na perspectiva de concretização da cidadania, ultrapassa a mera divulgação e a assessoria de imprensa, que caracterizam a autopromoção de governos, compreendendo a comunicação pública como um "instrumento facilitador do relacionamento entre cidadão e estado".

Com a intenção de minimizar as dúvidas em relação ao conceito, João Roberto Vieira da Costa (2006) e J. Ricardo de Mello Filho (2004) adotam "comunicação de interesse público" para substituir a expressão "comunicação pública". Dessa maneira, contextualizam de forma abrangente o sentido de "público", que extrapola a comunicação governamental, incluindo o universo estatal, o privado e o terceiro setor.

Apesar da tentativa válida de abolir os conflitos, a utilização de uma ou de outra expressão é apenas questão de escolha, uma vez que o cerne está na prática da comunicação pública e no interesse de quem a pratica. Se a intenção da administração pública é apenas autopromoção e da administração privada, a obtenção do lucro, o uso de uma ou de outra terminologia não implica praticar comunicação pública.

Para João Roberto Vieira da Costa (2006, p. 20), as ações de comunicação de interesse público têm como beneficiário direto a sociedade ou parte dela. Segundo o autor, o objetivo principal é "levar uma informação à população que traga resultados concretos para se viver e entender melhor o mundo". $O$ aspecto a se considerar é a relevância e a responsabilidade social dessa comunicação.

Para possibilitar que aconteça essa comunicação, que se quer pública, Mello (2004, p. 24) acentua que é preciso estabelecer, fortalecer e consolidar mecanismos e espaços de participação, apontando a necessidade de ir além da visão instrumental: 
A comunicação, a informação, o poder de decisão sobre as atividades governamentais constituem direitos dos contribuintes, da população em geral. O fato, ou pressuposto, é que a comunicação do estado brasileiro é, via de regra, limitada ao que foi descrito (marketing e assessoria de imprensa) (Grifo nosso). Mas não há dúvida de que é possível ir além, é obrigação do poder público ampliar seu raio de ação neste cenário.

Para o autor, a participação e o controle social na gestão pública possibilitariam a construção de administrações mais democráticas do que as atuais.

Observa-se que não há um conceito único de comunicação pública no Brasil. No entanto, há um ponto comum entre a maioria dos estudiosos desse assunto, que é a presença do interesse público na mensagem. Para facilitar a visualização desse enfoque, elaborou-se um quadro teórico (Quadro 1) com os principais conceitos contemplados nesta pesquisa:

\section{Quadro 1 - Resumo dos conceitos de comunicação pública}

\begin{tabular}{|l|l|}
\hline \multicolumn{1}{|c|}{ Autor } & \multicolumn{1}{|c|}{ Comunicação pública: conceitos } \\
\hline Pierre Zémor (1995) & $\begin{array}{l}\text { Aquela legitimada pelo interesse público, centrada no } \\
\text { cidadão. }\end{array}$ \\
\hline Jorge Duarte (2011) & $\begin{array}{l}\text { Deve viabilizar o direito social individual e coletivo à informa- } \\
\text { ção, à expressão, ao diálogo e à participação. O desafio da } \\
\text { comunicação pública é colocar a perspectiva, sobretudo, no } \\
\text { interesse público, na sociedade. }\end{array}$ \\
\hline $\begin{array}{l}\text { Maria José da Costa Oliveira } \\
\text { (2004, p. 199) }\end{array}$ & $\begin{array}{l}\text { "Assume o desafio de promover a educação com fim social, } \\
\text { aproximar os diferentes setores e desenvolver instrumentos } \\
\text { de prestação de contas, informação e conscientização junto } \\
\text { à sociedade. (...) Tem o papel de servir de interlocutora entre } \\
\text { os diferentes entes sociais, em prol do interesse público". }\end{array}$ \\
\hline Graça França Monteiro (2009) & $\begin{array}{l}\text { A singularidade não está no emissor, mas na mensagem } \\
\text { transmitida: de interesse público. Além disso, o objetivo não } \\
\text { é apenas informar, mas "qualificar o cidadão para exercer } \\
\text { seu poder de voto e de veto nas questões que dizem respei- } \\
\text { to à coletividade". }\end{array}$ \\
\hline Heloiza Matos (2011, p. 45) & $\begin{array}{l}\text { Os cidadãos são vistos como "produtores ativos no proces- } \\
\text { so". Para que a interlocução entre esses atores aconteça, } \\
\text { "é preciso criar espaços de discussão e deliberação sobre } \\
\text { temas políticos e sociais, espaços capazes de viabilizar a } \\
\text { formulação de demandas e sua consequente repercussão } \\
\text { no governo, na sociedade e na mídia". }\end{array}$ \\
\hline
\end{tabular}




\begin{tabular}{|l|l|}
\hline Mariângela Haswani (2009) & $\begin{array}{l}\text { Distingue a comunicação pública realizada por sujeitos pú- } \\
\text { blicos e a comunicação pública realizada por sujeitos de di- } \\
\text { reito privado, pelo dever e voluntarismo, respectivamente. }\end{array}$ \\
\hline João Roberto Vieira da Costa & $\begin{array}{l}\text { Adotam a expressão comunicação de interesse público, con- } \\
\text { textualizando de forma mais abrangente o sentido de "públi- } \\
\text { co", muito além da comunicação governamental, incluindo o } \\
\text { universo estatal, o privado e o terceiro setor. }\end{array}$ \\
\hline Costa (2006, p. 20) & $\begin{array}{l}\text { As ações de comunicação têm como beneficiário direto a } \\
\text { sociedade ou parte dela. O objetivo principal é "levar uma } \\
\text { informação à população que traga resultados concretos para } \\
\text { se viver e entender melhor o mundo". }\end{array}$ \\
\hline Mello (2004) & $\begin{array}{l}\text { Estabelecer, fortalecer e consolidar mecanismos e espaços } \\
\text { de participação. O autor integra interesse público às noções } \\
\text { de espaço público e cidadania, e questiona a comunicação } \\
\text { governamental realizada para construção da imagem e di- } \\
\text { vulgação de informações oficiais. Aponta a necessidade de } \\
\text { ir além e ampliar a visão instrumental da comunicação. }\end{array}$ \\
\hline
\end{tabular}

Fonte: Rosso (2012).

O conceito que expressa com pertinência a pretensão deste trabalho é que comunicação pública é toda comunicação legitimada pelo interesse público, pelo bem comum, visando, em primeiro lugar, beneficiar a população na busca por cidadania, seja essa comunicação praticada pelo estado, por instituições públicas, ONGs ou empresas privadas.

\section{O CASO DO MINISTÉRIO PÚBLICO DO TRABALHO NO PARANÁ}

O Ministério Público do Trabalho do Paraná (MPT-PR) busca a regularização das relações entre empregados e empregadores. Ele tem como prioridade: a erradicação do trabalho infantil e a regularização do trabalho do adolescente; o fim do trabalho forçado; a preservação da saúde e da segurança do trabalhador; o combate à discriminação; a formalização dos contratos de trabalho; o combate às irregularidades trabalhistas na administração pública; e o combate à exploração do trabalho portuário e aquaviário.

\section{A comunicação da instituição}

A instituição atua há 35 anos em defesa da legislação trabalhista no estado. No início era uma unidade de pequeno porte, mas cresceu rapidamente. Em 2011, contava com 49 procuradores e mais de 130 servidores, distribuídos na sede em Curitiba e nas nove unidades no interior do 
estado ${ }^{1}$. A gestão de comunicação do Ministério Público do Trabalho no Paraná é realizada pela assessoria de comunicação ${ }^{2}$ e pela assessoria de relações públicas e cerimonial, esta ligada diretamente ao gabinete da chefia. As duas assessorias, apesar de física e organizacionalmente separadas, atuam conjuntamente no planejamento e na execução de ações de comunicação. Cada uma desenvolve atividades específicas da área, apoiando-se mutuamente, até porque existe apenas um profissional responsável em cada um dos setores.

A assessoria de comunicação foi criada em 2005. Entre as finalidades básicas destacam-se: o planejamento e a execução de ações de comunicação, cujo objetivo é reforçar o conhecimento e o entendimento da sociedade sobre o papel da instituição, além de melhorar e estreitar o relacionamento com a imprensa, o público interno e a população.

Com a finalidade de promover maior aproximação com a sociedade, buscando democratizar a comunicação, o órgão utiliza diversos canais de comunicação direcionados aos cidadãos, como o site, o jornal externo InformAtivo, a ouvidoria, os fóruns de discussão, além da divulgação de notícias pela imprensa por meio de releases, entre outros. Entendemos que todos esses canais são importantes nos processos comunicativos da instituição, mas é inegável a relevância dos fóruns e da ouvidoria nesse contexto, justamente por promoverem maior abertura à participação da população, sendo essa uma das principais exigências da comunicação pública.

Como nosso objetivo é correlacionar a comunicação pública à prática da responsabilidade social do MPT-PR, e considerando que as informações e as mensagens são fundamentais nesse processo, por serem de responsabilidade da instituição, interessa-nos aqui focar os resultados obtidos no estudo que analisa a contribuição dos releases para sua comunicação pública.

\section{A análise dos releases}

O Ministério Público do Trabalho no Paraná, como qualquer instituição pública, tem obrigação de ser transparente, informar em que trabalha e como trabalha, salvo as exceções previstas em lei, como segredos de justiça. Com acesso às informações, uma das condições para o estabelecimento da comunicação pública, a sociedade pode avaliar se as propostas e ações estão de acordo com os interesses coletivos.

\footnotetext{
${ }^{1}$ No interior do Paraná, o Ministério Público do Trabalho está em Maringá, Londrina, Cascavel, Umuarama, Guarapuava, Ponta Grossa, Foz do Iguaçu, Campo Mourão e Pato Branco. A instalação de procuradorias nos municípios foi parte de um projeto nacional para aproximar a instituição dos cidadãos.

2 Quando, em 2005, foi criada a assessoria de comunicação ainda não existia a assessoria de relações públicas e cerimonial. Na época, como a assessoria era responsável por toda a comunicação da instituição (atendimento à imprensa, releases, clipping, jornal externo e interno, página externa e interna, etc.), entendeu-se oportuno não a chamar de assessoria de imprensa, mas de comunicação, por ser mais abrangente.
} 
Desde 2005, a assessoria de comunicação do MPT-PR faz a intermediação de notícias e busca fomentar o interesse dos jornalistas pelas pautas sobre o mundo do trabalho. Distribuem-se por ano entre sessenta e oitenta releases (Gráfico 1) sobre os mais diversos assuntos: cursos, termos de compromissos, ações, sentenças, na maioria com informações que beneficiam os trabalhadores e que também servem de orientação aos empregadores.

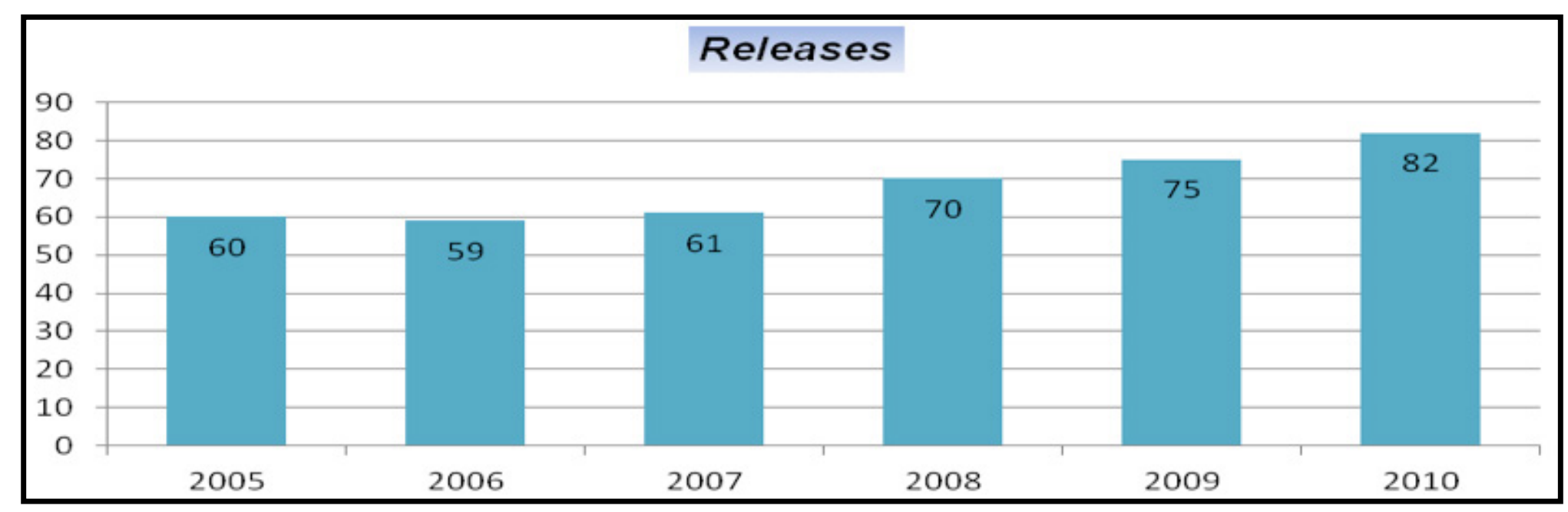

Gráfico 1 - Releases enviados à imprensa pela assessoria de comunicação do MPT-PR de 2005 a 2010

Na apreciação (análise de conteúdo) das mensagens transmitidas pelo órgão por meio dos releases em 2010, buscou-se verificar se eles se ancoram nas premissas da comunicação pública, principalmente no que se refere ao compartilhamento de informações relevantes para o cidadão. Entende-se que a publicização propiciada pela imprensa a questões de interesse público favorece o exercício da cidadania e contribui para o debate e a deliberação pública, além de possibilitar à instituição o processo de accountability. Mesmo que existam limitações relacionadas às condições de produção e de acesso da comunicação mediada, não há como deixar de concebê-la como um espaço público de interlocução para promover maior esclarecimento acerca de questões colocadas em cena.

Em 2010, foram produzidos 82 releases. O arquivo encontra-se disponível na "Sala de imprensa" no site da instituição (www.prt9.mpt.gov.br). Para a análise de conteúdo, quantitativa e qualitativa, agruparam-se os 82 releases em temas-chave. Em porcentagem, os releases agrupados ficaram assim representados:

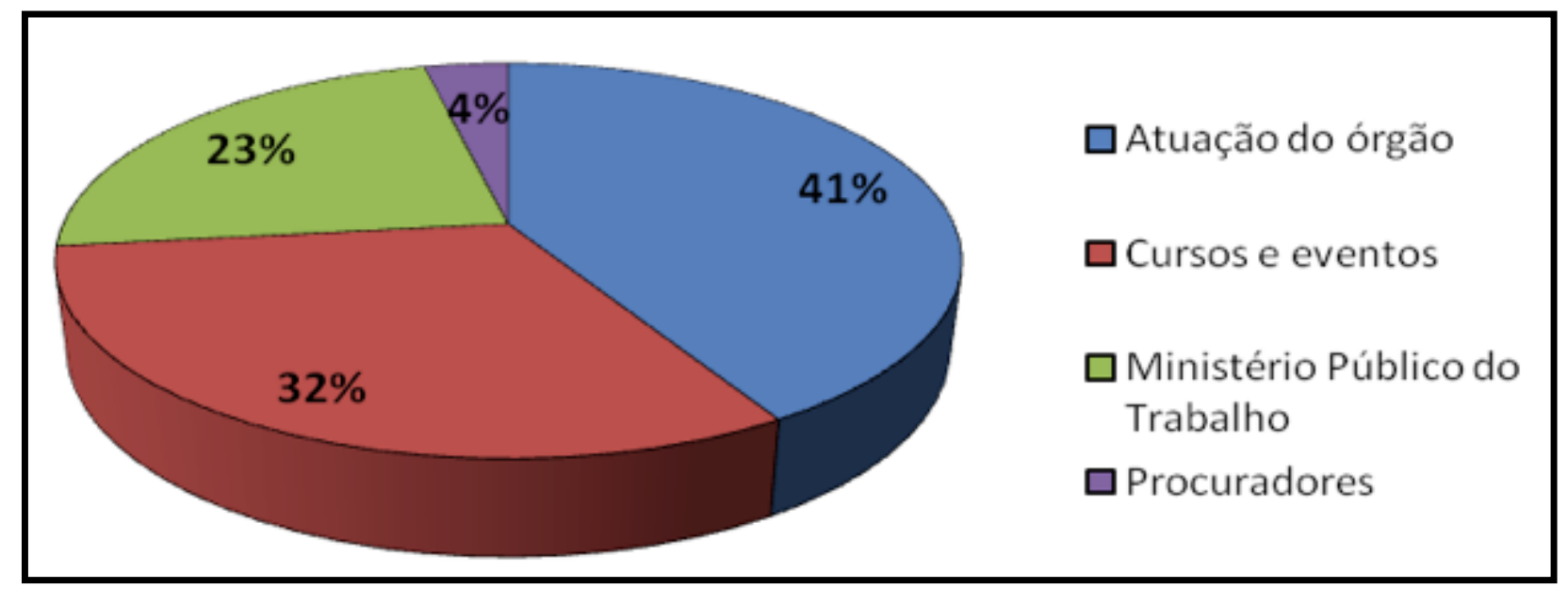

Gráfico 2 - Categorias temáticas dos releases 
A análise desenvolvida na amostra evidencia uma tentativa de os releases contribuírem para a tomada de consciência dos cidadãos, principalmente dos trabalhadores, uma vez que, informados, têm mais condições de exercer efetivamente seus direitos.

Em boa parte dos textos vislumbra-se a preocupação de apresentar a legislação trabalhista, sua violação pelos empregadores, os efeitos dessa conduta lesiva (acidentes de trabalho, doenças e morte) e, por fim, a atuação da instituição no combate a tais infrações. Essas informações visam instigar reflexões e mudanças de comportamento.

Com base na revisão bibliográfica e na análise de conteúdo, pode-se afirmar que os releases avaliados estão de acordo com os princípios da comunicação pública, principalmente pela temática abordada - o trabalho, além da presença de vários elementos característicos dessa comunicação, como interesse público, responsabilidade social, transparência pelo compartilhamento de informações, pretensão de serem levados a todos, indistintamente, e possibilidade de provocar o debate. Sendo assim, são fundamentais e contribuem para o processo de accountability, democratização e transparência.

Dos releases divulgados em 2010, 96\% tinham foco informativo e formativo, sendo que apenas $4 \%$ se enquadravam como autopromoção de personalidades. Do total de releases, a maior parte, $41 \%$, enfocava a atuação do MPT-PR, com informações sobre ações na Justiça, assinatura de termos de compromisso e combate a irregularidades. Aproximadamente $32 \%$ destacavam a realização de cursos, audiências e seminários. E 23\% apresentavam os serviços que a instituição disponibiliza, entre os quais a oferta de estágio e a habilitação de entidades para recebimento de multas e de material reciclado. Dessa forma, a instituição cumpria um dos papéis da comunicação pública - o de desenvolver a capacidade para o exercício da cidadania por meio de sua mensagem, que prioriza o interesse público acima do interesse privado e contribui para o desenvolvimento do indivíduo como cidadão, possibilitando reflexão e ação.

Ao publicizar pela mídia informações de interesse público relativas à sua atuação, o Ministério Público do Trabalho no Paraná cumpre com o dever constitucional de dar publicidade a seus atos. Essa publicidade não visa à promoção de autoridades ou de servidores, mas tem cunho educativo e/ou social, e almeja, sobretudo, facilitar o exercício da cidadania. Contudo, a socialização de informações não é suficiente. Jorge Duarte (2011) adverte que a simples existência de informação não necessariamente significa comunicação. Ela pode ser inútil, insuficiente, manipulada, mal compreendida ou não disponível quando necessária. A comunicação pública requer ultrapassar a informação e tornar públicos os atos. Nesse viés, as instituições precisam, sobretudo, compreender a amplitude dessa comunicação e vê-la como um direito de todos à cidadania.

\section{CONSIDERAÇÕES FINAIS}

No contexto geral, podemos dizer que o Ministério Público do Trabalho no Paraná, sob alguns aspectos, sustentado principalmente pela socialização de informações de interesse público e 
pela disponibilização de canais de participação e de deliberação pública, caminha em direção à concretização da comunicação pública, ao buscar construir espaços compartilhados e responsabilizar-se pela sua atuação na comunicação.

Cabe enfatizar que a comunicação pública, ou o seu ideal, é parte relevante no exercício da responsabilidade social de órgãos públicos, exigindo consciência e conhecimento por parte dos profissionais de comunicação que atuam nesse serviço público. Mesmo que ainda haja muitos obstáculos, precisa-se apoiar a gestão da comunicação na participação e na deliberação dos cidadãos. Essa extensão da comunicação é a esperança para se ampliar a democracia, tornando o cidadão corresponsável nas questões de interesse público e que afetam a vida em sociedade.

\section{REFERÊNCIAS}

BRANDÃO, Elizabeth Pazito. Conceito de comunicação pública. In: DUARTE, Jorge (Org.). Comunicação pública: estado, mercado, sociedade e interesse público. 2. ed. São Paulo: Atlas, 2009.

BUSATTO, Cézar A. O Ministério Público e a responsabilidade social. Disponível em: <http://www.vidademocracia. com/2008/07/o-ministrio-pblico-e-responsaabilidade.html>..Acesso em ago. 2012.

COSTA, João Roberto Vieira da. Comunicação de interesse público: ideias que movem pessoas e fazem um mundo meIhor (Org.). São Paulo: Jaboticaba, 2006.

DUARTE, Jorge. Sobre a emergência do(s) conceito(s) de comunicação pública. In: KUNSCH, Margarida M. Krohling (Org.). Comunicação pública, sociedade e cidadania. São Caetano do Sul (SP): Difusão, 2011.

HASWANI, Mariângela Furlan. O jornalismo disseminador de informações de serviços públicos governamentais no Brasil: colaboração ou desvio? In: CONGRESS OF THE LATIN AMERICAN STUDIES ASSOCIATION, Rio de Janeiro, junho de 2009. Disponível em: http://lasa.international.pitt.edu/members/ congress-papers/lasa2009/files/HaswaniMariangela.pdf. Acesso em: jun. 2011.

MAIA, Rousiley C. M. Visibilidade midiática e deliberação pública. In: GOMES, Wilson; MAIA, Rousiley C. M. Comunicação e democracia: problemas \& perspectivas. São Paulo: Paulus, 2008.

MATOS, Heloiza. Capital social e comunicação: interfaces e articulações. São Paulo: Summus, $2009 a$.

Comunicação pública, esfera pública e capital social. In: DUARTE, Jorge (Org.). Comunicação pública: estado, mercado, sociedade e interesse público. 2. ed. São Paulo: Atlas, $2009 \mathrm{~b}$.

. A comunicação pública na perspectiva da teoria do reconhecimento. In: KUNSCH, Margarida M. Krohling (Org.). Comunicação pública, sociedade e cidadania. São Caetano do Sul (SP): Difusão, 2011.

MELLO FILHO, J. Ricardo R. de. Comunicação de interesse público: a escuta popular na comunicação pública: tentando construir uma nova política. Recife: Fundaj / Ed. Massangana, 2004.

MONTEIRO, Graça França. A singularidade da comunicação pública. In: DUARTE, Jorge (Org.). Comunicação pública: estado, mercado, sociedade e interesse público. 2. ed. São Paulo: Atlas, 2009. 
NOVELLI, Ana Lucia R. O papel institucional da comunicação pública para o sucesso da governança. Organicom - Revista Brasileira de Comunicação Organizacional e Relações Públicas, Gestcorfp/ECA-USP, a. 3, n. 4, p.75-89, $1^{\circ}$ sem. 2006.

OLIVEIRA, Maria José da Costa. Comunicação pública. Campinas (SP): Alínea, 2004.

REIS, Patrícia Cerqueira. Tevê pública digital: análise da política pública para um espaço midiático interativo, participativo e democrático. In: KUNSCH, Margarida M. Krohling (Org.). Comunicação pública, sociedade e cidadania. São Caetano do Sul (SP): Difusão, 2011.

ROSSO, Gisele. Processos comunicativos na perspectiva da comunicação pública: o caso do Ministério Público do Trabalho no Paraná. 2012. Dissertação (Mestrado em Comunicação) - UFPR, Programa de Pós Graduação em Comunicação, 2012.

ZÉMOR, Pierre. La Communication publique. Paris: PUF, 1995. Tradução resumida do livro: Elizabeth P. Brandão. Disponível em: <http://pt.scribd. com/doc/38276509/ ComunicacaoPublicaPierreZemor-traducao>. Acesso em: 09 jul. 2010.

Recebido em: 03.09.2012 / Aceito em: 09.05.2013 